\title{
Subjetividade, marxismo e Serviço Social: um ensaio crítico*
}

\author{
Subjectivity, Marxism and Social Services: a critical essay
}

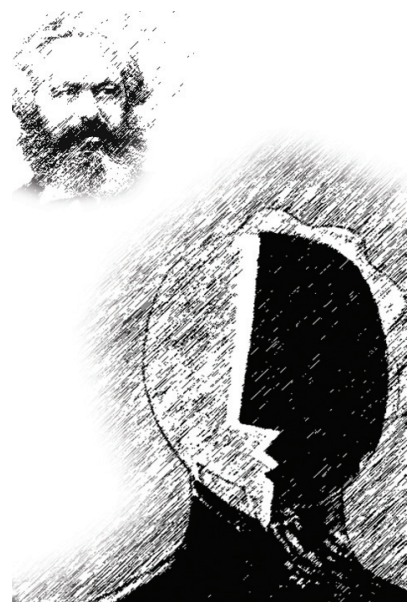

\section{Marco José de Oliveira Duarte**}

\begin{abstract}
Resumo: A partir da polêmica teórica e política sobre a relação entre marxismo e psicanálise, inauguradao pela perspectiva crítica da Escola de Frankfurt, e tomando como referência o debate acadêmico e o exercício profissional do Serviço Social contemporâneo em que a temática da subjetividade vem se apresentando com forte conteúdo psicologista, o artigo propõe-se a contribuir na superação do tradicionalismo colocando a temática na agenda ética, política e acadêmica no cenário profissional.
\end{abstract}

Palavras-chave: Marxismo. Subjetividade. Psicanálise. Serviço Social. Trabalho profissional.

\begin{abstract}
From the theoretical and policy debate about the relation between Marxism and psychoanalysis - debate that was inaugurated by the School of Frankfurt's critical perspective - and taking the academic debate and the professional activity of the contemporary Social Services, in which subjectivity is presented with a strong psychological content, the article contributes to over-

* Artigo apresentado originalmente na disciplina Trabalho e Serviço Social na América Latina, coordenada pela profa. dra Marilda Villela Iamamoto no curso de Doutorado em Serviço Social, no PPGSS-FSS-UERJ e, ao obter nota máxima, indicado para publicação.

** Assistente social, psicólogo e sanitarista, mestre em Serviço Social (UFRJ, 1993), especialista em Saúde Coletiva (Unicamp, 2002) e doutorando em Serviço Social (UERJ). Professor, pesquisador e extensionista do Departamento de Fundamentos Teórico-Práticos do Serviço Social da Faculdade de Serviço Social da UERJ e atualmente seu diretor. Coordenador do Núcleo de Estudos, Pesquisa e Extensão em Saúde Mental e Atenção Psicossocial — Neps da UERJ; supervisor clínico-institucional do CAPS-UERJ (Centro de Atenção Psicossocial da UERJ) pela Gerência da Atenção Psicossocial da Prefeitura Municipal do Rio de Janeiro/RJ - Brasil, além de ministrar a disciplina de Estágio Supervisionado em Serviço Social na área da Saúde Mental e desenvolver atividades de assessoria, consultoria e supervisão na área. E-mail: psicossocial.uerj@gmail.com
\end{abstract}


come traditionalism by setting the theme in the ethical, academic and policy agenda in the professional scene.

Keywords: Marxism. Subjectivity. Psychoanalysis. Social Services. Professional work.

\section{Introdução}

O inferno dos vivos não é algo que será; se existe, é aquele que já está aqui, o inferno no qual vivemos todos os dias, que formamos estando juntos. Existem duas maneiras de não sofrer. A primeira é fácil para a maioria das pessoas: aceitar o inferno e tornar-se parte dele, até o ponto de deixar de percebê-lo. A segunda é arriscada e exige atenção e aprendizagem contínuas: tentar saber reconhecer, de dentro do inferno, o que não é inferno, e preservá-lo, e abrir espaço. (Calvino, 1990, p. 148)

o tomarmos a problemática da subjetividade, tendo como referên-
cia de análise o marxismo para entendermos como se processa esse
debate no âmbito do Serviço Social, foi necessária uma pequena
incursão na revisão da literatura especializada nessas temáticas. No entanto, entendemos que muito ainda deve ser investigado, dada a envergadura de tal análise, mas que, para atendermos aos objetivos deste trabalho, apresentaremos alguns elementos introdutórios para um ensaio crítico, crendo que muito deverá ser aprofundado teórico-metodologicamente.

Nesse processo, nos deparamos e observamos que não há um trato analítico específico em Marx sobre a temática da subjetividade, e isso não o descarta ou invalida no debate acadêmico, ao contrário. Por outro lado, dizer que há uma redução nos estudos marxistas sobre o tema é decerto uma crítica superficial da obra marxiana e da tradição marxista, dada a importância que tem sido dada a essa temática no debate que vem sendo travado no campo diverso e plural da teoria social crítica, incluindo aí a própria psicanálise com seus artigos de cunho social e não só, destaque aqui para os autores da Escola de Frankfurt. ${ }^{1}$

1. Adorno, Horkheimer, Fromm e Marcuse (primeira geração do Instituto de Pesquisa Social), Habermas (segunda geração) e Honneth, Benhabib, Cohen e Young como integrantes da terceira e última geração. Alguns 
Pretendemos desenvolver melhor algumas notas introdutórias neste quadro, que aqui se apresenta de forma extremamente simplificada, a fim de questionar a versão privada do tema da subjetividade no campo profissional do Serviço Social e propor que, por meio do significante usuário - cidadão (tão em voga na atualidade), a psicanálise retome seu lugar na tradição do pensamento crítico no Serviço Social no sentido de compreender o mal-estar individual como sintoma do mal-estar social.

\section{Marxismo e psicanálise: a reafirmação da temática da subjetividade na teoria social crítica}

Aqui, se faz necessário, nessas pequenas linhas, colocar no debate a relação da psicanálise e o marxismo e posteriormente ressaltar a interlocução do Serviço Social com essa perspectiva, que desde os seus primórdios de sistematização em terreno americano, em particular, não foi feito com a psicanálise freudiana, mas sim com o psicologismo americano, denominado psicologia do ego ou neopsicanálise. Por isso é claro entender certa refutação na produção intelectual da profissão em sua gênese, também a passos largos e bem distantes com o legado da teoria social crítica no questionamento sobre a cultura e a civilização burguesa. Esse mesmo saber profissional restringiu a sua fundamentação na psicologização das relações sociais, tendo em vista que seu paradigma se baseou no estrutural-funcional de T. Parsons.

No entanto, em toda a tradição crítica do Serviço Social, a partir dos anos 1980, com a sua renovação e rompimento com a perspectiva tradicional da profissão, esse mesmo Serviço Social relegou a interlocução e a introdução da

\footnotetext{
desses autores foram comumente identificados como freudo-marxistas, incluindo nesse W. Reich, que não fez parte do referido instituto alemão. Essa problematização a respeito da relação do marxismo e da psicanálise freudiana, começa quando os pensadores da teoria crítica se interessam sobretudo pela "teoria freudiana da cultura", desenvolvida a partir dos anos 1920, quando Freud introduz o conceito de "pulsão de morte", pois ela revela a profunda relação que une o desenvolvimento social e a constituição psíquica dos indivíduos. Mas é bem verdade que poderia ser estendida ao conjunto da teoria crítica, uma vez que todos os seus integrantes trataram da questão em diversos textos. Esse empreendimento foi realizado no Brasil por S. P. Rouanet (1989).
} 
psicanálise, entendendo-a ainda como um pensamento conservador que subsidiou teórico-metodologicamente a perspectiva tradicional da profissão, traduzida como Serviço Social de caso, Serviço Social de grupo e até mesmo como Serviço Social clínico, com seu enfoque nas relações humanas, no relacionamento com o cliente, na resolução do problema social do cliente, para enumerar algumas noções.

Mas cabe sinalizar que a temática da subjetividade, mesmo no interior do próprio marxismo, também teve essa repulsa por parte de alguns teóricos e críticos, como bem ressalva Silveira (2002, p. 7),

a temática da subjetividade no campo do marxismo tende a ser tratada com estranhamento, não só porque no âmbito do senso comum difunde-se um antagonismo entre o campo da singularidade e o dos projetos coletivos, mas porque, igualmente, no interior da própria esquerda, a questão da produção dos sujeitos vem sendo considerada de forma preconceituosa e/ou reducionista.

A interpretação social da obra de Freud aqui realizada deve ser entendida no contexto da crítica marxista da sociedade de massas contemporânea, mas de um marxismo não ortodoxo. Com o desenvolvimento histórico, alguns autores repensaram e questionaram os conceitos e concepções do marxismo e, nesse processo, a teoria freudiana adquiriu um papel fundamental.

A relação entre o marxismo e a teoria freudiana deve ser entendida como sendo dois momentos que se completam e se refutam. Eles se completam na medida em que o marxismo apresenta o processo objetivo de exploração e subjugação do indivíduo, no modo de produção capitalista, desmistificando esse processo social e econômico por meio da "crítica da economia política": enquanto "linguagem do todo", o marxismo representa o universal. Já a psicanálise representa esse processo social na perspectiva do sujeito, de seu efeito no processo de subjetivação, que surge da relação dialética com outros sujeitos, indivíduos, grupos, organizações e instituições: ela representa o particular, isto é, a dimensão subjetiva do longo processo de dominação e exploração denunciado por Marx.

O marxismo e a psicanálise freudiana expressam os dois lados de um mesmo "fato", digamos assim, duas perspectivas de uma mesma realidade, a do 
indivíduo "cindido", explorado, assujeitado, hierarquizado e alienado. Neste sentido, eles se completam. Enquanto o marxismo apresenta a base social deste processo, a psicanálise apresenta a base psíquica correspondente, que é por ele produzida, ao mesmo tempo em que o mantém e o reproduz. Assim, a psicanálise é a "linguagem do singular" na qual o todo é passível de ser reconhecido.

O marxismo e a psicanálise se refutam na medida em que não podem ser unidos numa disciplina totalizante - "essas teorias são o limite negativo uma da outra, são dois modos de explicar a realidade da sociedade alienada, dois instrumentos de análise cujo uso é determinado pelas exigências do objeto" (Rouanet, 1989, p. 76). ${ }^{2}$

A "fusão do marxismo e da psicanálise constituiria uma traição às intenções críticas dos seus respectivos autores" (Rouanet, 1989, p. 74). A linha que separa a psicanálise do marxismo só poderia ser abolida por meio de uma transformação social efetiva, que eliminasse o antagonismo entre o universal e o particular, entre as exigências da sociedade repressiva (de sua manutenção e perpetuação) e as exigências e necessidades individuais — esta separação testemunha um fato empírico, o da real separação entre o indivíduo e a sociedade.

A relação do marxismo e da psicanálise, na teoria crítica, deve ser compreendida na relação dialética entre o universal (dimensão social) e o particular (dimensão psíquica), entre o indivíduo e a sociedade.

A relação de Freud e Marx [na teoria crítica] é dialógica e não sistemática. No máximo, são duas falas, que se confirmam, se refutam, se cancelam: dois motivos

2. Em 1921, na Rússia pós-revolucionária, Vera Schmidt fundou um centro educativo que recebeu o nome de Lar Experimental de Crianças. Era uma instituição pedagógica que aplicava às crianças os princípios do marxismo e da psicanálise. Nessa escola, o sistema tradicional de castigos corporais foi extinto, o antigo ideal de família patriarcal foi severamente criticado em prol de valores educativos que privilegiavam a necessidade coletiva. As crianças, criadas fora de qualquer influência religiosa, eram autorizadas a satisfazer sua curiosidade sexual. Os próprios educadores eram, por sua vez, instados a não reprimir a masturbação e a tratar as crianças em relação de igualdade. Ademais, todos os participantes do programa deveriam ser analisados. Essa primeira experiência do freudo-marxismo durou até 1924, quando, em virtude completa falta de apoio da conservadora Associação Internacional de Psicanálise, e sabotada pela reação da burocracia do Estado, Vera Schmidt teve que abandonar o projeto. Esse recuo não se deu só com essa experiência, mas com várias outras que podemos relatar e em outros campos de intervenção social que o espaço deste trabalho não nos permite expor. 
em contraponto, no interior de uma sinfonia, mais que duas teorias no interior de um sistema [...] sua essência está, justamente, nessa relação dialógica entre Marx e Freud, em que as duas doutrinas funcionam como limites negativos uma da outra, relativizando-se e relativizando qualquer pretensão totalizante. (Rouanet, 1989, p. 76)

Destaca-se aqui que esse entendimento acima é contrário o que defende a Psicologia do Ego, como uma neopsicanálise, com seu caráter revisionista da própria teoria psicanalista, pois eliminou determinados conceitos e enfocou outros, reforçando-os e revisando-os, como, por exemplo, o seu privilegiamento da função do ego em oposição ao inconsciente e com isso, a oposição entre indivíduo e sociedade. Seria de igual forma, se pensássemos em um neomarxismo que eliminaria substancialmente do marxismo a luta de classes, "privando tanto o freudismo quanto o marxismo de seu conteúdo" (Rouanet, 1989, p. 50).

Assim, no revisionismo, a "questão política" referente à transformação da sociedade se torna em uma "questão moral", ou seja, "confrontados com o dilema entre alterar o freudismo ou a realidade, preferiram alterar o freudismo" (Idem, p. 222), recaindo, dessa forma, em um revisionismo psicologizante do ego, o que influenciou todo campo de outros saberes, como o Serviço Social.

O "pessimismo" freudiano implica em uma recusa em compartilhar essa realidade opressiva e causadora de doenças psíquicas (neuroses, perversões etc.) e sofrimento humano (angústia, melancolia), elementos tão presentes para a teoria e a prática psicanalítica. A análise do indivíduo em Freud não pressupõe referenciais normativos, adaptadores e ajustadores, mas surge da própria mediação social.

Apesar das transformações históricas que afetaram o objeto da psicanálise — o sujeito do desejo —, mesmo assim os conceitos freudianos ainda se mantêm relevantes na compreensão da realidade, uma vez que sua acusação à civilização não foi ultrapassada por um novo estágio de organização social: os processos e conflitos psíquicos que a teoria freudiana descreve não desapareceram - eles continuam existindo, mas agora se dão de forma diferente e devem ser analisados tendo em vista esse fato.

A análise da sociedade contemporânea por meio do instrumento da teoria freudiana implica assim uma crítica deste instrumento (Rouanet, 1989). Não somente a teoria freudiana, mas também o marxismo participa dessa lógica. A 
teoria freudiana possui um "limite histórico", enquanto instrumento de análise e crítica da sociedade. Esse limite refere-se à ambiguidade presente na psicanálise freudiana, entre, de um lado, a crítica avassaladora da civilização (cujas imposições são fonte de sofrimento humano) e, de outro, a conclusão de que esse sofrimento é inevitável: a psicanálise "dobra-se diante do princípio de realidade", sendo, ao mesmo tempo, "crítica da ilusão" e "perpetuadora da falsa consciência [...]. Ao mesmo tempo em que mostra que a infelicidade é produto da cultura, Freud postula a infelicidade como condição inerente à vida social" (Idem, p. 94).

A teoria freudiana se refere a uma concepção de indivíduo e de civilização que possibilita seu uso enquanto instrumento de análise e de crítica da sociedade. Assim, o "pessimismo freudiano" reflete uma postura essencialmente crítica de Freud para com o processo civilizatório. Partindo da perspectiva individual, analisando o sofrimento, a angústia, a infelicidade e as várias doenças psíquicas, Freud chega à conclusão de que esse sofrimento é causado por uma civilização que nega, pela sua própria estrutura e organização, a satisfação e a felicidade aos indivíduos.

Ele descobriu, portanto, na análise da "doença individual", a "doença geral" da civilização. Preserva em suas concepções e conceitos a realidade tal como ela se apresenta, e não uma realidade idealizada. O indivíduo em Freud é infeliz, reprimido, não possui autonomia, sendo determinado, tanto em nível filogenético (história da espécie) quanto ontogenético (história individual).

Esse "realismo pessimista" (ou "pessimismo crítico") de Freud permite romper com a "cegueira" frente a uma realidade opressiva, que se apresenta como harmônica (Rouanet, 1989). Ao afirmar a oposição entre a satisfação das necessidades e desejos individuais e as exigências da sociedade, Freud apresenta a realidade tal como ele a vê: em sua forma alienada.

Entretanto, Freud aceitou problematizar a oposição entre felicidade e civilização burguesa - e aqui a teoria freudiana no seu conceito de mal-estar aponta criticamente para as contradições e transformações da sociedade industrial moderna. Percebemos um conteúdo crítico presente em seus fundamentos, o que nos permite pensar sobre as novas políticas de subjetivação assumidas hoje pela sociedade capitalista que cada vez mais reforçam essas contradições 
nas possibilidades de libertação e emancipação do humano que lhe são intrínsecas e que ao mesmo tempo são possíveis e reais.

O termo políticas de subjetivação se refere a um processo contínuo de produção social da subjetividade no que diz respeito à criação, bem como à mortificação, da vida humana em sua integralidade. Dito de outra forma, a subjetividade não é uma instância privada e estanque do meio, também não é um receptáculo desse mesmo meio. Há entre subjetividade e sociedade uma produção que se dá em conjunto. Assim, determinadas condições de vida criam formas de se estar no mundo. Os aspectos econômicos e culturais, a cidade, o emprego e o desemprego, a escolaridade e o analfabetismo, o medo, a violência, a miséria, os fundamentalismos religiosos, as guerras, as etnias, as diferenças, os preconceitos, a solidariedade, os projetos de vida, a falta de perspectiva, as políticas públicas, dentre tantos outros aspectos, se misturam e dão corpo ao que se chama subjetividade. Todas as políticas que se encontram em curso no campo social produzem e expressam, ao mesmo tempo, modos de vida. (Machado, 2008, p. 191)

Desta forma, a nosso ver, podemos afirmar criticamente que as categorias freudianas que definiam o psiquismo e a sociedade em determinado momento histórico, assim como a relação entre ambos, não se sustenta mais na nova configuração da sociedade capitalista mundializada.

Por outro lado, a noção de conflito é central em Freud ${ }^{3}$ — como a contradição em Marx —, tanto no que se refere à formação psíquica individual, quanto na relação entre as exigências de satisfação pulsional e a sociedade. Esse conflito parece que foi contido pela sociedade "unidimensional", pela sua capacidade de integrar as forças antagônicas e a negação. Assim, podemos assegurar que as categorias freudianas tornaram-se "obsoletas" na realidade atual. Entretanto, esta "obsolescência" das categorias freudianas revela maior repressão, e não maior liberdade. Se a teoria freudiana não pode mais explicar, a partir de seus próprios conceitos, como se dá a relação entre o indivíduo e a sociedade, é porque essa sociedade se transformou.

No entanto, vemos a possibilidade de repensar no seio do próprio marxismo, introduzindo neste uma preocupação com o sujeito: aqui a teoria freudiana fornece o suporte teórico. Mas, para se tornar uma teoria "crítica", a teoria

\footnotetext{
3. A esse respeito ver Fontes, 2008.
} 
freudiana precisa ser questionada, e este processo se dá por meio da crítica imanente aos seus conceitos, tendo em vista as transformações históricas ocorridas - essa crítica elucida o "movimento" desses conceitos.

A teoria freudiana possibilita o objetivo de "crítica" somente decifrando a dialética histórica de seus conceitos. Assim, ela pode dar origem a algo de novo e sua crítica à civilização pode se tornar construtiva — ao contrário da interpretação revisionista da neopsicanálise americanista, que imobiliza a sua "função crítica".

Essa "função crítica" da teoria freudiana está na denúncia do elo entre infelicidade e civilização: na medida em que os revisionistas afirmam a possibilidade da felicidade na civilização e não questionam os seus fundamentos, eles se tornam ideológicos.

Freud foi um crítico feroz da civilização, pois ele tinha consciência do vínculo que une progresso e infelicidade. Se ele afirma a infelicidade como uma condição necessária da civilização, é porque é muito mais humano do que aqueles que creem que é possível a felicidade se realizar nessa sociedade. Se a felicidade for concebida apenas individualmente, ela é falsa.

O programa de tornar-se feliz, que o princípio do prazer nos impõe, não pode ser realizado; contudo não devemos — na verdade, não podemos — abandonar nossos esforços de aproximá-lo da consecução, de uma maneira ou de outra. (Freud, 1977, p. 146)

A felicidade e a liberdade são perspectivas, são condições que só podem ser concebidas quando todos os indivíduos tiverem acesso às riquezas produzidas (Heller, 1982) pela "sociedade da abundância", e não apenas por um grupo restrito de pessoas de determinada classe, e, sobretudo, quando a produção dessa riqueza não estiver mais vinculada ao aumento da exploração e da miséria, à destruição e ao sucateamento do meio ambiente e dos seres humanos.

Habermas (1987, p. 109) afirma que

As deformações de um mundo da vida regulamentado, analisado, controlado e protegido são, certamente, mais refinadas do que formas palpáveis de exploração 
material e empobrecimento. Mas nem por isso os conflitos sociais deslocados e internalizados no psíquico e no corpóreo são menos destrutivos.

\section{Serviço Social e subjetividade: apontamentos desafiadores}

Nesse emaranhado de contradições e perspectivas, somos inclinados a observar que o Serviço Social, como afirmamos anteriormente, caminhou a passos largos e bem distantes, tanto nos seus primórdios como na contemporaneidade, de uma interlocução com a psicanálise em sua fonte original, mas vem tentando dialogar com alguns representantes do conjunto de obras e autores que constituem o que se convencionou chamar de teoria social crítica, sejam elas modernas, pós-modernistas e/ou contemporâneas.

Iamamoto (2007, p. 237) em sua pesquisa sobre o balanço crítico da literatura profissional sobre os fundamentos do Serviço Social e ao seu exercício, nas duas últimas décadas, identifica

um significativo avanço no que concerne à crítica teórico-metodológica tanto do conservadorismo quanto do marxismo vulgar [...]. Esse avanço se expressa na ultrapassagem da mera denúncia do tradicionalismo profissional ao efetivo enfrentamento de seus dilemas tanto na construção da crítica teórica quanto na elucidação de seus limites socioculturais e políticos na condução do trabalho profissional; no empenho em superar os "metodologismos" a favor de uma proximidade do Serviço Social com as grandes matrizes do pensamento social na modernidade, delas extraindo os fundamentos teórico-metodológicos para a explicação da profissão e para iluminar as possibilidades de sua atuação.

Cabe destacar que Iamamoto aponta para a ampla e diversificada tradição marxista nessa análise da produção acadêmica no Serviço Social. Assim, a autora se debruça sobre as elaborações teóricas que "matizam o debate teórico entre pares de um mesmo projeto profissional" e demonstra que

grande parte das diferenças (mais que antagonismos) entre os autores decorre tanto da angulação particular pela qual a profissão é abordada quanto da variedade das fontes teóricas - as quais se inspiram, centralmente, em Marx, Hegel, Lukács, Gramsci, Hobsbawm e Thompson - que iluminam a formulação das indagações que norteiam as pesquisas dos autores. (Iamamoto, 2007, p. 331) 
Entretanto, as duas teorias gerais abordadas aqui, psicanálise e marxismo, em momentos diferentes, possuem o mesmo estatuto teórico-metodológico no Serviço Social. Se a interlocução do Serviço Social com o marxismo, em suas primeiras leituras, foram de forma enviesada e influenciada pelo positivismo, o mesmo pode-se dizer da psicanálise de cunho adaptador, ajustador, conservador e reformista que influenciou o mesmo Serviço Social.

Cabe, assim, nesse lastro dos últimos vinte anos no amadurecimento intelectual da profissão, inaugurar também um debate de ruptura com o resgate do tema da subjetividade no Serviço Social pelo viés da crítica teórica e metodológica presente no cenário profissional.

Neste sentido, é necessário registrar, neste texto, um esforço de sistematização de determinados autores no Serviço Social que vêm investigando e produzindo sobre esse tema, e demarcando uma diferença por dentro do campo profissional, como Bisneto (2007), Vasconcelos (2000) e Nicácio (2008). ${ }^{4}$

O núcleo comum com relação à crítica elaborada por eles e do qual compartilho funda-se, principalmente, com o que já introduzimos aqui, mas que tentamos sintetizar, pois concordamos que o Serviço Social, enquanto ramo do saber, não tinha a capacidade intelectiva e crítica de fazer naquele momento o que pode fazer hoje, sem reprodução mecânica do idealismo moral do ser social burguês na sua intervenção profissional e produção científica, o que só está sendo possível no contexto da renovação profissional em solo brasileiro.

O Serviço Social nos Estados Unidos se muniu de vários referenciais teóricos para pautar sua atuação, principalmente o funcionalismo, o estrutural-funcionalismo, o higienismo e as psicologias. As escolas psicológicas americanas do Serviço Social (diagnóstica e funcional) absorveram as teorias de várias linhas da psicologia clássica. Foi significativa a contribuição da psicanálise no processo de tentativa de elaboração de uma metodologia em Serviço Social [...], em especial na área de saúde mental. (Bisneto, 2007, p. 19)

Vasconcelos (2000) afirma que a psicanálise absorvida pelo Serviço Social norte-americano identifica-se com a psicologia do ego, e foi influenciada por

4. No que se refere às referências profissionais, o primeiro é assistente social e os outros dois são psicólogos. 
Otto Rank e Alfred Adler, bem como por Anna Freud e pelo triunvirato nova-iorquino Kris, Hartmann e Loewenstein.

Nicácio (2008, p. 3-4) afirma que,

A psicanálise possui suas diferenciações internas. A corrente psicanalítica que serviu de fundamento teórico para o serviço social de casos foi a americana, autodenominada psicologia do ego. Esta corrente psicanalítica advogava o fortalecimento do ego para que ele fosse capaz de dominar suas pulsões e, assim, se adaptar melhor a seu ambiente social. O ideal de cura para esses analistas era o adulto bem-sucedido na sua vida produtiva, vivendo em harmonia na sua família e no seu casamento. Em suma, um cidadão bem adaptado. Dentro do próprio movimento psicanalítico esta corrente foi objeto de duras críticas, desferidas pelo psicanalista francês Jacques Lacan. A psicologia do ego na sua concepção teria posto de lado as descobertas fundamentais de Freud sobre o inconsciente [...]. Lacan chegou mesmo a afirmar que esta versão americana da psicanálise se tornou uma "ideologia" adaptacionista ou mais uma técnica de "human engeneering".

Por outro lado, se a temática da subjetividade no Serviço Social tradicional, digamos assim, foi influenciada pelo conservadorismo, a sua reatualização pela fenomenologia por dentro da área profissional deixou a desejar, pois limitou-se ao chamado "vivido" da situação interna do "cliente" (ente) sem levar em consideração a transversalidade da política no trabalho profissional, reduzindo a temática da subjetividade que estamos fazendo à crítica nesse momento.

Cabe destacar que os que se alinham nessa perspectiva são os mesmos que atualizam o Serviço Social de caso pela nomenclatura do Serviço Social clínico, que em nada tem a ver com as atribuições privativas do assistente social definidas pelo conjunto da categoria profissional no Brasil. Assim para essa intervenção profissional, para uma clínica stricto sensu, o referido profissional precisa de uma formação apropriada em instituições específicas. Então ele deixa de ser profissional de Serviço Social para ser profissional de outro tipo: terapeuta de família, psicoterapeuta ou até mesmo psicanalista.

No entanto, quando estamos introduzindo a discussão da temática da subjetividade não estamos pretendendo o retorno à psicologização, como estamos criticando. Porém entendemos que o conteúdo da relação entre os sujeitos produz valor de uso na medida em que 
sendo a força criadora de trabalho condição vital do trabalhador, alienada como meio de assegurar sua própria vida, não existe como coisa objetiva, mas como subjetividade, como capacidade de um ser vivo, cuja manifestação não se faz real até que o capital a solicite, porque a atividade sem objeto não é nada. Tão logo a força de trabalho é colocada em movimento pelo capital, converte-se em atividade produtiva - o trabalho — , manifestação de existência vital do trabalhador, orientada para um determinado fim, o que só ocorre no processo produtivo. Essa é uma das características distintivas da mercadoria força de trabalho do ponto de vista de seu valor de uso. (Marx, apud Iamamoto, 2007, p. 180-181)

Essa dimensão de valor é que estamos tentando problematizar, pois a crítica ao psicologismo com a qual concordamos não pode descartar por completo toda a dimensão subjetiva do trabalho profissional, que Vasconcelos (2000) aponta no significante do recalque.

Nesse sentido, Iamamoto (2007), afirma que não existe um processo de trabalho do Serviço Social, e sim trabalho do assistente social:

O trabalho, força de trabalho em ação, é algo temporal, que só pode existir no sujeito vivo. Enquanto gasto vital, é um movimento criador do sujeito - , que, no seu contexto de alienação, metamorfoseia-se no seu contrário, ao subjugar seu próprio criador à condição de criatura —, impregnando a totalidade de seu ser: capacidades, emoções, ritmos do corpo, pensamento e valores. Assim, o trabalho como elemento subjetivo do processo de trabalho é componente da humanidade dos sujeitos, em processo de realização: é objetivação do sujeito e, simultaneamente, subjetivação da realidade pelo sujeito. (p. 429; grifos nossos)

Nesse contexto, podemos dizer que a conceituação de subjetividade presente na obra de Foucault, Guattari e Deleuze (Duarte, 2000) se coaduna com uma acepção de histórica que estamos produzindo aqui: desnaturalizada, sem unidade e sem uniformidade, tendo em vista que os modos de subjetivação colocam-se como subjetividades sempre em processo de mutação. Modos de subjetivação seriam antes maneiras, disposições, meios sempre diversos com que as configurações subjetivas se engendram no contexto sócio, histórico, político, cultural e econômico para sua compreensão real, e não só na esfera do trabalho, que, segundo Marx (1985, p. 148), "não produz só mercadoria, produz 
a si mesmo e ao trabalhador como uma mercadoria, e isto na proporção em que produz mercadorias em geral".

Quando se fala "a minha subjetividade", a "minha opinião", o "meu desejo", não se trata de algo interno que se revela ao exterior. As formas subjetivas são compostas socialmente. ${ }^{5}$ Todo sujeito é sempre coletivo. Assim, quando falo, muitas vozes falam em mim, muitas histórias atravessam a minha história, e isso se torna mais complexo quando se pensa no terreno da intervenção e nos postos de trabalho profissional. Embora haja uma composição singular em mim, que me difere dos demais, que difere cada um, somente a composição é singular. Os pedaços de que é feita são partilhados por muita gente.

Nesse sentido, um pressuposto que se impõe diz respeito à consideração de que a subjetividade é socialmente produzida, operando numa formação social determinada, sob o crivo de um determinado tempo histórico e no âmbito de um campo cultural [...] Marx vai organizar essa vinculação a partir da análise do homem inserido no processo produtivo e produzindo-se. (Silveira, 2002, p. 104)

Percebe-se, assim, que os regimes de dominação que estão em curso em nosso tempo produzem o "individualismo" como desejo e como necessidade. ${ }^{6}$ Demarcar distinções se parece como apólices de seguro de competências e sucesso, deixando-se de ser solidário. Ao mesmo tempo, cada um de nós se perde em meio a uma massa homogênea de gente que pensa igual, se veste igual, deseja igual. As diferenças, ao contrário do que poderíamos supor, são pouco exercidas, raras são as singularizações desse processo, tanto em grupo como em coletivos, socialmente instituídas (Duarte, 1999).

Fontes, ao apontar para pontos comuns e diferenças importantes no diálogo entre Freud e Marx, coloca que o estatuto de conflito em um e outro é radicalmente diferente, embora ambos admitam a transformação e o princípio da historicidade radical, e esse princípio, segundo a autora, "se encontra exatamente

5. Iamamoto (2001) aborda de outra forma essa questão entre indivíduo concreto e individualidade social.

6. Rouanet (1993) afirma que uma das críticas da esquerda é chamar Freud de individualista, pois para Freud o indivíduo foi sempre um inimigo potencial. 
na forma pela qual os indivíduos são constituídos pelo conflito" (2008, p. 120). No entanto, cabe sinalizar que um enfoca em sua práxis a transformação singularizada, enquanto o outro, o processo de transformação dos modos de existência social — ou "das formas de modos de ser" (Marx, 1985).

É importante destacar a compreensão de que o sujeito atual que intenta plasmar na sociabilidade do mundo contemporâneo é cada vez mais egoico, autocentrado, descrente das esferas coletivas, competitivo, eficiente, eximido das responsabilidades sociais e morais. Assim, o projeto societário hoje hegemônico - o do capital - é aceito e internalizado pelos sujeitos, através de mediações institucionais, normatizações e legislações legitimadoras de uma igualdade anunciada, ainda que formal, para a qual se atribuem regulações e disciplinamentos democráticos que irão dar sustentabilidade legal à desigualdade instituída. Assim, reproduz-se de outra forma, o modo de produção capitalista. Neste contexto, o sujeito mesmo, mercadoria, coisifica-se, se fragiliza e se fragmenta, desfigurando-se na qualidade de produtor de coisas e de sua própria consciência.

A concepção de subjetividade ${ }^{7}$ com a qual o marxismo vai romper, e que está presente no âmbito da hegemonia burguesa, é a que supõe o indivíduo na qualidade de ente abstrato e idealizado, por conseguinte, exterior às efetivas relações sociais capitalistas. Por consequência, nessa abstração, ele pode ser "modelado" (Silveira, 2002, p. 110-111), estratégia de controle e disciplinamento do capital.

Atualmente, nas sociedades ocidentais, cada vez mais observamos que a subjetividade é trocada pelo individualismo, pela privacidade, pela intimidade, pelo egocentrismo radical, causando a alienação da realidade, uma razão descolada da racionalidade emancipatória e social, e "uma apatia mais complexa com relação às grandes questões de interesse comum" (Rouanet, 1993, p. 22), que cada vez mais são típicas do neoliberalismo em tempos de globalização: "intimismo individualista, imaginário introspectivo e a fixação em razões fan-

7. Martins (1992, p. 34) diz que "por mais estranho que isso possa inicialmente soar, parece-nos que a definição mais básica de subjetividade em Marx é a sua já citada formulação direta e quase truística: a subjetividade é uma determinação do sujeito, enunciado que se tornou necessário diante da pressuposição hegeliana de uma subjetividade pura, que prescindia de qualquer suporte nos sujeitos humanos reais". 
tasmáticas e fantasiosas que proporcionam uma regressão psicológica" (Bisneto, 2007, p. 186).

Eis o nosso desafio enquanto assistente social no trabalho profissional nas organizações institucionais diversas: tomar a temática da subjetividade articulada com as discussões da agenda política da categoria profissional, tanto no seu exercício quanto na formação profissionais (Duarte, 2009), principalmente quando se trava um debate sobre as formas de emancipação humana. ${ }^{8}$

\section{Traçando algumas considerações (in)conclusivas...}

Como o profissional está assujeitado nesse processo social, é parte integrante nessa engrenagem, pois é contratado como força de trabalho especializada para acionar essas máquinas tecnológicas que operam centralmente na lógica direta da modelagem das subjetividades humana (Duarte, 2006) e vital dos sujeitos, já que lida no cotidiano profissional e institucional, ou seja, nas relações sociais.

Ora, a fabricação social e histórica da subjetividade não é um tema novo no campo das ciências sociais e humanas. Com certeza, no Serviço Social, há muito que galgar, principalmente a partir desse novo patamar acadêmico com a crítica que se operou no passado recente. Mas se muito se fez, é verdade que

8. Semeraro (1999, p. 72-73) tratando do conceito de subjetividade como a contribuição de Gramsci ao marxismo contemporâneo, aponta que esse autor "não cansa de repetir que as concepções que sustentam a iniciativa e o desenvolvimento da subjetividade são próprias de um grupo social que se propõe a ser sujeito e protagonista da história. A subjetividade, de fato, é a típica maneira de ser das classes dirigentes, de quem exercita uma relação ativa com a realidade. Não se podia, portanto, pensar na emancipação dos trabalhadores enquanto se mantinha a submissão às regras e aos princípios da classe dominante. Para desenvolver no operário a 'psicologia do produtor' e colocar a nova classe fundamental em condição de dirigir o processo histórico, era necessário desenvolver posições antitéticas à ordem existente. Mas a ruptura, a 'cisão', não era suficiente. Havia, principalmente, necessidade de elaborar e de concretizar um projeto de sociedade superior ao da classe dominante [...]. Então, o ponto central das reflexões de Gramsci se prende à formação de novos sujeitos sociais que visam à construção de um projeto de sociedade aberto à participação de todos os trabalhadores. Nesse sentido, a consciência e a subjetividade representam uma dimensão fundamental na ação política, uma vez que se é verdade que não é a consciência que determina o ser social, é também verdade que só por meio da consciência o homem pode apropriar-se das funções da sociedade e ter condição de realizá-las lutando contra as pressões externas que condicionam seu comportamento e neutralizam suas aspirações". 
ainda há muito o que fazer, tomando como foco que lidamos com sujeitos reais e concretos, que sentem, pensam, agem e sofrem os efeitos da desigualdade social, expressões da questão social, do sucateamento das políticas sociais e das redes de proteção social operadas pelo Estado.

Diríamos, didaticamente, que há uma corporeidade no usuário dos serviços sociais, como: etnias, gêneros, raças, sexualidades, sexos, religiosidades enfim, um todo complexo que não se reduz mas que atravessa as classes sociais, sem, contudo, desmerecê-las na realidade social brasileira. Nesse bojo, o usuário que procura e que demanda ajuda ou orientação ao assistente social tem sempre uma relação "problemática e ambígua com sua situação de fragilidade, de sofrimento, em função de alguma perda ou fragilidade que ele enfrenta, e isso está marcado no seu psiquismo" (Nicácio, 2008, p. 17).

O que queremos sinalizar nestas linhas é que não é porque o assistente social tem uma abertura para o outro, quando atende e escuta ${ }^{9}$ essas problemáticas e conflitos apresentadas pelo sujeito que ele recebe, seja no plantão social, na entrevista social, na visita domiciliar, e que são sociais, que ele está psicologizando as relações sociais, ou mesmo tendo uma atitude de psicoterapia atribuição privativa dos psicólogos. Isso tem sido mais um reducionismo do raciocínio dualista de uma crítica que não dialoga nem mesmo com a sua própria cultura profissional, já que boa parte de nossas técnicas ou ferramentas interventivas foi "sequestrada" de outros saberes técnico-científicos socialmente reconhecidos originalmente.

Afinal, quando lidamos com uma dimensão que não se limita às ações burocráticas e mesmo idealizadas no cotidiano do trabalho profissional, seja individualmente ou em grupo, somos afetados nessa relação de intersubjetividades, como bem demarcou os pensadores freudo-marxistas. Não se pode manter a neutralidade científica, o distanciamento asséptico da racionalidade técnica ou recalcar todos os sentimentos, impulsos e emoções que são imanentes. Ao contrário, isso demonstra que há um hiato entre o que se tem produzido

9. Segundo Nicácio (2007), "ato que não é privativo de nenhuma profissão". No entanto, é necessário registrar que segundo Freud, definido em sua originalidade, é um ato de atenção flutuante, rompido com a ordem médica do ouvir pelo ouvir, sentido biológico. 
sobre essa realidade dos usuários das políticas socais e até mesmo sobre essas políticas sociais e esse lidar no cotidiano do trabalho profissional. Muito embora digamos que podemos ocupar - e ocupamos — os lugares de planejamento e gestão das políticas sociais, isto não significa que nesses postos de exercício profissional, ou na execução dessas mesmas políticas não sejam afetos a essa dimensão concreta e social que é a subjetividade humana.

Só a título de exemplo, o sofrimento e o adoecimento não são entidades abstratas, e em quase todos os espaços institucionais e organizacionais em que se opera a interlocução entre saberes, práticas, políticas, agenciamentos enfim, racionais e tecnológicos, elas se materializam por intermédio dos sujeitos reais, no caso, do profissional. É por essa razão que, segundo dados colhidos sobre saúde mental e saúde do trabalhador, o profissional de Serviço Social é a categoria de trabalhadores que mais sofre na relação de trabalho, no conjunto de outras categorias profissionais, no campo social e da saúde, com psicopatologia do trabalho, de fadiga crônica, e não só. Percebe-se, sem muito aprofundamento, por meio de observação empírica ainda, de outros tipos de sofrimento psíquico, como em particular a depressão, ou mesmo de doenças psicossomáticas, como o câncer. Ou seja, somos afetados em todas as atividades humanas e, em particular, no trabalho produtivo, pelas consequências econômicas e históricas do modo de produção capitalista que cada vez mais afetam subjetividades e corporeidades, como expropriação da mais-valia.

A contribuição deste ensaio não se limita às linhas aqui escritas, mas se fará presente no debate teórico e político sobre o trabalho profissional e nas organizações em que esse trabalho se encontra, pois no cotidiano profissional e institucional no contexto das políticas públicas e privadas, na esfera pública e privada dos sujeitos em relação, estamos implicados com outros, na disputa, na política, na correlação de forças e nos modos de a(fe)tivação e de produção de subjetividades contemporâneas.

Não estamos perdidos. Pelo contrário, venceremos se não tivermos desaprendido a aprender. (Rosa de Luxemburgo, 1983, p. 116)

Artigo recebido em out./2009 a Aprovado em jan./2010 


\section{Referências bibliográficas}

BISNETO, J. A. Serviço Social e saúde mental: análise profissional da prática. São Paulo: Cortez, 2007.

Análise institucional, Serviço Social e subjetividade: uma introdução. Transversões I (1), Rio de Janeiro, v. 1, n. 1, p. 132-168, 1999.

CALVINO, I. As cidades invisíveis. São Paulo: Companhia das Letras, 1990.

DUARTE, M. J. de O. Por uma cartografia do cuidado em saúde mental: repensando a micropolítica do processo de trabalho do cuidar em instituições. In: BRAVO, M. I. S. et al. (Orgs.). Saúde e Serviço Social. 4. ed. São Paulo: Cortez, 2009.

Assessoria na área de Serviço Social e saúde mental: conversações. In: BRAVO, M. I. S.; MATOS, M. C. (Orgs). Assessoria, consultoria \& Serviço Social. Rio de Janeiro: Faperj, 7 Letras, 2006.

Da análise institucional à micropolítica: contribuições para um estudo. Em Pauta, Rio de Janeiro, n. 16, p. 121-135, jan./jul. 2000.

Os cuidadores e o cotidiano do cuidado em um serviço de saúde mental. Em Pauta, Rio de Janeiro, n. 14, p. 85-93, jan./jul. 1999.

FONTES, V. Historicidade e subjetividade. Contradição e conflito, liberdade e determinação. In: FONTES, Virgínia. Reflexões im-pertinentes: história e capitalismo contemporâneo. Rio de Janeiro: Bom Texto, 2008.

FREUD, S. Obras psicológicas completas. (Mal-Estar da Civilização). Rio de Janeiro: Imago, 1977.

HABERMAS, J. A nova intransparência - a crise do Estado de Bem-Estar Social e o esgotamento das energias utópicas. Novos Estudos Cebrap, São Paulo, n. 18, p. 103-114, set. 1987.

HELLER, A. Para mudar a vida: felicidade, liberdade e democracia. São Paulo: Brasiliense, 1982.

IAMAMOTO, M. V. Serviço Social em tempo de capital fetiche. São Paulo: Cortez, 2007.

Trabalho e indivíduo social. São Paulo: Cortez, 2001.

LUXEMBURGO, Rosa. Camarada e Amante: Cartas de Rosa de Luxemburgo a Leo Jogiches. Rio de Janeiro: Paz e Terra, 1983. 
MACHADO, L. Políticas de subjetivação. In: MANFROI, Vania Maria; MENDONÇA, Luiz Jorge Vasconcellos Pessôa (Orgs.). Política social: trabalho e subjetividade. Vitória: Edufes, 2008.

MARTINS, M. V. Marxismo e subjetividade: uma leitura dos "Manuscritos de 44". In: BAPTISTA, Luís Antônio dos S. (Org.). Anuário do Laboratório de Subjetividade e Política. Niterói: Eduff, 1992, ano 1, v. 1.

MARX, K. O capital. crítica da economia política. São Paulo: Abril, 1985. v. 1.

MONTEIRO, L. G. M. Neomarxismo: indivíduo e subjetividade. São Paulo: EDUC; Florianópolis: Edufsc, 1995.

MINAYO, M. C. de S. Estrutura e sujeito, determinismo e protagonismo histórico: uma reflexão sobre a práxis da saúde coletiva. Ciência e Saúde Coletiva, Rio de Janeiro, v. 6, n. 1, p. 7-19, 2001.

NICÁCIO, E. M. Serviço Social e subjetividade. Praia Vermelha - Estudos de Política e Teoria Social, Rio de Janeiro, n. 18, segundo semestre, p. 46-70, 2008.

ROUANET, S. P. Mal-estar na modernidade. São Paulo: Companhia das Letras, 1993.

Teoria crítica e psicanálise. Rio de Janeiro: Tempo Brasileiro, 1989.

SCHAFT, A. Marxismo e indivíduo. Rio de Janeiro: Civilização Brasileira, 1967.

SEMERARO, G. Da sociedade de massa à sociedade civil: a concepção da subjetividade em Gramsci. Educação \& Sociedade, São Paulo: ano XX, n. 66, p. 65-83, abr. 1999.

SÈVE, L. Marxismo e a teoria da personalidade. Lisboa: Horizonte Universitário, 1979.

SILVEIRA, P.; DORAY, B. Teoria marxista da subjetividade. São Paulo: Vértice, 1989.

SILVEIRA, M. L. S. da. Algumas notas sobre a temática da subjetividade no âmbito do marxismo. Outubro, São Paulo, n. 7, p. 103-113, 2002.

VASCONCELOS, E. M. (Org.). Abordagens psicossociais. São Paulo: Hucitec, 2008. v. 1 .

Saúde mental e Serviço Social: o desafio da subjetividade e da interdisciplinaridade. São Paulo: Vozes, 2000. 